ARTICLE

https://doi.org/10.1038/s41467-019-08619-x

\title{
Lithium promoted mesoporous manganese oxide catalyzed oxidation of allyl ethers
}

\author{
Biswanath Dutta1, Ryan Clarke (10 1, Sumathy Raman², Timothy D. Shaffer ${ }^{2}$, Laura Achola1, \\ Partha Nandi ${ }^{2} \&$ Steven L. Suib ${ }^{1,3}$
}

Herein we report the first example of the catalytic aerobic partial oxidation of allyl ether to its acrylate ester derivative. Many partial oxidations often need an expensive oxidant such as peroxides or other species to drive such reactions. In addition, selective generation of esters using porous catalysts has been elusive. This reaction is catalyzed by a $\mathrm{Li}$ ion promoted mesoporous manganese oxide (meso- $\mathrm{Mn}_{2} \mathrm{O}_{3}$ ) under mild conditions with no precious metals, a reusable heterogeneous catalyst, and easy isolation. This process is very attractive for the oxidation of allyl ethers. We report on the catalytic activity, selectivity, and scope of the reaction. In the best cases presented, almost complete conversion of allyl ether with near complete chemo-selectivity towards acrylate ester derivatives is observed. Based on results from controlled experiments, we propose a possible reaction mechanism for the case in which $\mathrm{N}$-hydroxyphthalimide (NHPI) is used in combination with trichloroacetonitrile $\left(\mathrm{CCl}_{3} \mathrm{CN}\right)$.

\footnotetext{
${ }^{1}$ Department of Chemistry, University of Connecticut, U-3060, 55 North Eagleville Road, Storrs, CT 06269, USA. ${ }^{2}$ Corporate Strategic Research, ExxonMobil, 1545 US 22 East, Annandale, NJ 08801, USA. ${ }^{3}$ Institute of Materials Science, University of Connecticut, U-3060, 55 North Eagleville Road, Storrs, CT 06269, USA. Correspondence and requests for materials should be addressed to P.N. (email: partha.nandi@exxonmobil.com) or to S.L.S. (email: steven.suib@uconn.edu)
} 
crylics and acrylates ${ }^{1-3}$ have become important building blocks for the chemical industry today. Acrylates are key ingredients for producing dyes, glues, papers, adhesives, binders, paints, and thickeners ${ }^{4,5}$. The industrial source of acrylics and acrylates is propylene that is produced as either the byproduct of fluid catalytic cracking (FCC $)^{6}$, steam cracking, or by propane dehydrogenation ${ }^{7}$. Propane or propylene can be subsequently oxidized to acrylates via the Mitsubishi process ${ }^{8}$ or propene ammoxidation ${ }^{9-11}$ using mixed metal oxides. These processes involve the formation of acrylonitrile intermediates that are converted into acrylates, acrylamides, and acrylic acids depending on the reaction condition employed ${ }^{12}$. Typically these oxidations are run around $450^{\circ} \mathrm{C}$, where formation of ethylene, $\mathrm{HCN}$, acetonitrile, $\mathrm{N}_{2} \mathrm{O}$, and $\mathrm{CO}_{2}$ by-products are unavoidable.

Recently, several homogeneous processes have been recognized for efficiently oxidizing allylic $\mathrm{C}-\mathrm{H}$ bonds ${ }^{13-15}$. Peroxides and $\mathrm{N}$ hydroxides were used for synthesizing various enones via allylic $\mathrm{C}-\mathrm{H}$ oxidation ${ }^{14}$. However, these methodologies primarily focus on cyclic unsaturated molecules. Crystalline manganese oxide based materials (e.g., K-OMS-2) are used for various catalytic transformations including the selective oxidation of alcohols to aldehydes ${ }^{16}$, hydrocarbons to alcohols and ketones ${ }^{17}$, styrenes to styrene oxides ${ }^{18}$, alcohols to amides ${ }^{19}$, amines to imines ${ }^{20}$, some oxidative coupling reactions, such as alkynes to di-ynes ${ }^{21}$, alkynesilanes $^{22}$, anilines to azobenzenes ${ }^{23}$, and dehydrogenative oxidation reaction of alkanes ${ }^{24}$.

These mixed valent manganese oxide materials have numerous structural forms with high thermal stability ${ }^{25}$. The reduction of $\mathrm{Mn}^{4+/ 3+}$ to $\mathrm{Mn}^{3+/ 2+}$ releases labile lattice oxygen atoms, which are responsible for their catalytic performance ${ }^{21,25}$. These lattice oxygens act as basic sites for $\mathrm{H}$ abstraction during the reaction. This eliminates the requirement of using a base with mesoporous manganese oxides for oxidative dehydrogenations ${ }^{26}$. Moreover, the presence of alkali and alkaline earth metal ions in the manganese oxide lattice enhance catalytic activity. Basicity increases due to the attraction of lattice oxygens toward these electropositive ions. We therefore introduced these types of ions in the allylic $\mathrm{C}-\mathrm{H}$ oxidation reactions. These mesoporous manganese oxide materials, developed by an inverse-micelle method, were selected for their comparatively high surface areas compared with traditional mesoporous transition metal oxides ${ }^{27}$.

In this paper, acrylates have been directly produced via an aerobic catalytic oxidation process. Allyl ethers were used in this low-temperature process with lithium ion impregnated mesoporous manganese oxides as heterogeneous catalysts. An advantage of these catalysts is that manganese oxides are abundant and inexpensive materials. Conversions of diallyl ether as high as $95 \%$ with selectivities to allyl acrylate greater than $99 \%$ were achieved via optimization of the reaction conditions. Such studies suggest that NHPI-air, hydrogen peroxides, and $\mathrm{CCl}_{3} \mathrm{CN}$ are essential in controlling activity, selectivity, and stability of these catalysts. Control experiments were done to determine the interrelationships of these critical factors in these oxidation reactions. A plausible mechanism is proposed based on mechanistic studies. Such studies suggest that radical intermediate formation, followed by successive hydroxylation and oxidation are significant for this reaction. Mobility of lattice oxygen in the meso- $\mathrm{Mn}_{2} \mathrm{O}_{3}$ catalysts and $\mathrm{CCl}_{3} \mathrm{CN}$ promoted PINO radicals are the significant requirements in this catalytic process.

\section{Results}

Reaction conditions. The interdependence and synergistic effect of the reaction parameters spurred us to evaluate and compare reaction conditions (Supplementary Figs. 1 and 2). Reaction kinetics under different set of conditions were investigated.
$\mathrm{NHPI}-$ air- $\mathrm{CCl}_{3} \mathrm{CN}$ emerged with the highest rate constant of $2.82 \mathrm{~min}^{-1}$, while NHPI- $\mathrm{N}_{2}-\mathrm{CCl}_{3} \mathrm{CN}$ displayed the slowest rate constant of $0.3 \mathrm{~min}^{-1}$ (Supplementary Table 6, entry 1 and 4). Moreover, reaction under NHPI-air with no $\mathrm{CCl}_{3} \mathrm{CN}$ displayed a rate constant of $0.57 \mathrm{~min}^{-1}$, which was slightly lower than 0.71 $\mathrm{min}^{-1}$ of the TBHP-CCl ${ }_{3} \mathrm{CN}$ system (Supplementary Table 6, entry 2 and 3 ). The fourfold increase in activity for NHPI-air- $\mathrm{CCl}_{3} \mathrm{CN}$ than the TBHP- $\mathrm{CCl}_{3} \mathrm{CN}$ system proved its superiority. A ninefold decrease in activity upon replacing air with nitrogen and a fivefold decrease in the absence of $\mathrm{CCl}_{3} \mathrm{CN}$, proved their significance. These studies helped evaluate the importance of reaction parameters. According to the results obtained, reaction conditions which increase the reaction rate are ranked as follows: $\mathrm{NHPI}-\mathrm{O}_{2}-\mathrm{CCl}_{3} \mathrm{CN}>\mathrm{TBHP}-\mathrm{CCl}_{3} \mathrm{CN}>$ $\mathrm{NHPI}-\mathrm{O}_{2}-$ no $\mathrm{CCl}_{3} \mathrm{CN}>\mathrm{NHPI}-\mathrm{N}_{2}-\mathrm{CCl}_{3} \mathrm{CN}$. In all cases, these kinetic experiments revealed a first-order rate dependence with respect to the starting material allyl ether. Further characterization was done with X-ray powder diffraction and BET surface area measurements (Supplementary Fig. 6). Various reactants and products were analyzed with nuclear magnetic resonance (NMR), See Supplementary Note 1.

Substrate scope. The substrate scope and limitations were then explored using structurally different ethers, with each possessing at least one allylic $\mathrm{CH}_{2}$ group. Under optimized reaction conditions, diallyl ether and cyclic dihydrofuran (Table 1, entry 1 and 3) were transformed to their corresponding oxidized products exclusively with 92 and 99\% yields, respectively. On the other hand, allyl acetate and allyl glycidyl ether (Table 1, entry 2 and 4) were transformed to their oxidized counterpart with 60 and $66 \%$ yields, respectively. However, a poor yield of $12 \%$ was obtained for allyl phenyl ether (Table 1, entry 5). Hyperconjugation and the loss of a proton from the a-carbon was easier in the case of allyl ether than that of phenyl allyl ether (B. E. $=67.2 \pm 0.5$, and $81.84 \pm 0.5 \mathrm{kcal} / \mathrm{mol}$, respectively, Table 1$)$. This resulted in better stability and poorer reactivity of the phenyl allyl ether than the allyl ether. To investigate the reason for selective formation of monoesters over the anhydride, density functional theory (DFT) calculations were conducted, using the CBS-QB3 basis set. DFT results show that $\mathrm{C}-\mathrm{H}$ bond dissociation energy of allylic $\mathrm{C}-\mathrm{H}$ of diallyl ether is $80.8 \mathrm{kcal} / \mathrm{mol}$, which significantly increases to 82.7 $\mathrm{kcal} / \mathrm{mol}$ for the allyl acrylate ester C-H. A smaller increase in bond dissociation energy was observed when comparing reactants and products in Table 1, entry 3. Perhaps the cyclic nature of the substrate binding to the catalyst surface further limited the oxidation of the lactone to the corresponding anhydride. In Table 1, entry 4 the glycidyl $\mathrm{C}-\mathrm{H}$ bond in the reactant is a competing site for oxidation with a calculated BDE of $91.2 \mathrm{kcal} / \mathrm{mol}$. Upon oxidation of the allylic $\mathrm{C}-\mathrm{H}$ bond the glycidyl $\mathrm{C}-\mathrm{H}$ bond becomes stronger at $95.7 \mathrm{kcal} / \mathrm{mol}$. Probably for similar reasons, no activation of $\mathrm{a}-\mathrm{C}-\mathrm{H}$ bonds was noted in 1-butene and ethyl substituted allyl ethers (Table 1, entry 6 and 7).

Stability and reusability. To determine if the observed catalysis is a result of leached active sites, the solid catalyst was separated from the reaction mixture by hot filtration after $45 \mathrm{~min}$ (about $25 \%$ conversion). The resulting filtrate was then subjected to reaction conditions for an additional $315 \mathrm{~min}$. Aliquots were collected successively after each hour and were analyzed with GCMS to track the progress of the reaction. No further improvement in GC yield was observed after the first $2 \mathrm{~h}$ (Supplementary Fig. 3), indicating no further conversion of substrate in the absence of a catalyst. The same filtrate was also analyzed by inductively coupled plasma mass spectrometry (ICP-MS), which 


\section{Table 1 Substrate scope of the reaction protocola}

\begin{tabular}{|c|c|c|c|c|c|c|c|}
\hline No. & Substrate & $\begin{array}{l}\text { Calculated } \\
\text { BDE }^{\text {b }} \\
\text { (kcal/mol) }\end{array}$ & Product & $\begin{array}{l}\text { Calculated } \\
\text { BDE }^{\text {b }} \\
\text { (kcal/mol) }\end{array}$ & $\begin{array}{c}\text { Conversion } \\
(\%)^{c}\end{array}$ & Yield $^{d}$ & TOF $^{e}$ \\
\hline 1. & & 80.8 & 0 & 82.7 & 92 & $\begin{array}{l}91 \\
(79)\end{array}$ & 1.9 \\
\hline $2 .^{f}$ & & 87.2 & & -- & 60 & 59 & 0.9 \\
\hline 3. & & 78.2 & & 78.9 & $>99$ & $\begin{array}{l}98 \\
(92)\end{array}$ & 2.1 \\
\hline 4. ${ }^{f}$ & & 79.3 & & -- & 66 & $\begin{array}{l}65 \\
(59)\end{array}$ & 1.0 \\
\hline $5 .^{\mathrm{g}}$ & & 81.8 & & -- & 12 & 12 & 0.5 \\
\hline 6. & & -- & 0 & -- & 7 & 7 & N/A \\
\hline 7. & & -- & & -- & n.d & n.d & N/A \\
\hline
\end{tabular}

aReaction condition: substrate ( $2 \mathrm{mmol}$ ), Temp- $80^{\circ} \mathrm{C}$, solvent- $2.5 \mathrm{~mL}$, Catalyst- meso- $\mathrm{Li}-\mathrm{Mn}_{2} \mathrm{O}_{3}(25 \mathrm{mg}), \mathrm{NHPI}(25 \mathrm{~mol} \%), 6 \mathrm{~h}$ and air balloon. ${ }^{\mathrm{b} B o n d}$ dissociation energies (BDE) were calculated by DFT using CBS-OB3 basis set. Numbers in parenthesis are the isolated yields. ${ }^{\circ}$ Conversions and selectivities were determined by GC-MS (in all cases $>99 \%$ selectivity were obtained). ${ }^{\mathrm{d}}$ Yield $=$

Conversion $\times$ selectivity $(\%)$, e TOF $=$ TON/h, TON $=$ mole of ether converted to the product over mole of catalyst used. ${ }^{\mathrm{f}} 8 \mathrm{~h}, \mathrm{~g} 16 \mathrm{~h}$

indicated the presence of a very low amount $(165 \mathrm{ppm})$ of Manganese (Mn).

To verify reusability, the catalyst was retrieved (>90\%) after the reaction by simple filtration and washed with excess acetonitrile and methanol. The catalyst was reactivated prior to reuse at $250{ }^{\circ} \mathrm{C}$ for $30 \mathrm{~min}$ under air to remove any adsorbed substrates. As evident from Supplementary Fig. 4, the catalyst was successfully reused for three more cycles with less than a 50\% drop in activity. The decrease in activity is probably due to metal poisoning $\left(\mathrm{Mn}^{\mathrm{III}}\right)$, caused by the strong coordination of different radicals with the metal centers. Therefore, our catalyst can be considered as truly heterogeneous, stable, and moderately reusable.

\section{Discussion}

Based on the above-mentioned observations, we propose mechanisms by both TBHP- $\mathrm{CCl}_{3} \mathrm{CN}$ and NHPI-air- $\mathrm{CCl}_{3} \mathrm{CN}$ catalysts. The role of manganese species during the reaction can be correlated with the work reported by Ishii et al. using electron paramagnetic resonance (EPR) measurements ${ }^{28}$. To further understand our systems, EPR data for the acetonitrile solution of NHPI with and without meso- $\mathrm{Mn}_{2} \mathrm{O}_{3}$ under atmospheric condition were compared. There was a decrease in the EPR signal, which could be due to the formation of an extra radical (possibly PINO) in the former reaction at $g=2.0073$ (Supplementary Fig. 5). This suggest the formation of a superoxomanganese (IV) or $\mu$-peroxomanganese (IV) complex between $\mathrm{Mn}^{\mathrm{III}}$ and $\mathrm{O}_{2}$. In both cases, a series of steps contributed to the formation of monoesters from the allyl ethers. Manganese oxides $\left(\mathrm{Mn}^{\mathrm{IV}}\right.$-oxide, 1) have been reported to react with molecular oxygen to form $\mathrm{Mn}^{\mathrm{IV}}$-peroxide radicals (2) (Fig. 1). These are considered to be very reactive and are expected to deprotonate the NHPI molecule to form a PINO radical and a $\mathrm{Mn}^{\mathrm{IV}}$-hydrogen peroxide (3) species. A competition between PINO radical and $\mathrm{Mn}^{\mathrm{IV}}$-peroxide radical (2, is expected during the deprotonation of allylic hydrogens (5). The corresponding radical (6) is believed to couple with an oxygen molecule and $\mathrm{Mn}^{\mathrm{II}}$ species to form an intermediate 7 that upon reacting with a molecule of NHPI (4) produced a $\mathrm{Mn}^{\mathrm{III}}$-PINO (11) and allyl ether-hydrogen peroxide (8) species. The latter went through further rearrangements with the loss of an oxygen moiety to generate the desired allyl acrylate (10), whereas the $\mathrm{Mn}^{\mathrm{III}}$-PINO (11) regenerated the TBHP and $\mathrm{Mn}^{\mathrm{II}}$ species. 
The mechanism in the presence of TBHP is expected to follow a similar mechanism to that of the NHPI catalyzed pathway (Fig. 2). A fourfold decrease in the rate constant (i.e., from 2.82 $\mathrm{min}^{-1}$ for NHPI-O${ }_{2}-\mathrm{CCl}_{3} \mathrm{CN}$ to the $0.71 \mathrm{~min}^{-1}$ by TBHP- $\mathrm{CCl}_{3} \mathrm{CN}$-based reaction) discouraged us from using this catalytic system. Moreover, we have independently determined that $\mathrm{Mn}_{2} \mathrm{O}_{3}$ is an extremely potent material for decomposing TBHP into $\mathrm{t}-\mathrm{BuOH}$ and $\mathrm{O}_{2}{ }^{29}$. Since $\mathrm{O}_{2}$ is highly abundant and cheap, we focused our work using $\mathrm{O}_{2}$ as an oxidant, not only due to the relatively poor rates of TBHP- $\mathrm{CCl}_{3} \mathrm{CN}$ system.

In both cases, probably an intermediate 6 type radical was oxidized to form an $\alpha$-hydroxy ether (9). The transformation of intermediate 8 to $\mathbf{9}$, probably resulted in the release of oxygen, which are the terminal oxidants of the catalytic process (Fig. 1). Though the fate of this oxygen is known, their method of interaction in the oxidation process is still unknown. An ahydroperoxide intermediate is likely to be formed, which, however, is very difficult to trap in rapid oxidations over manganese oxide $^{30}$.

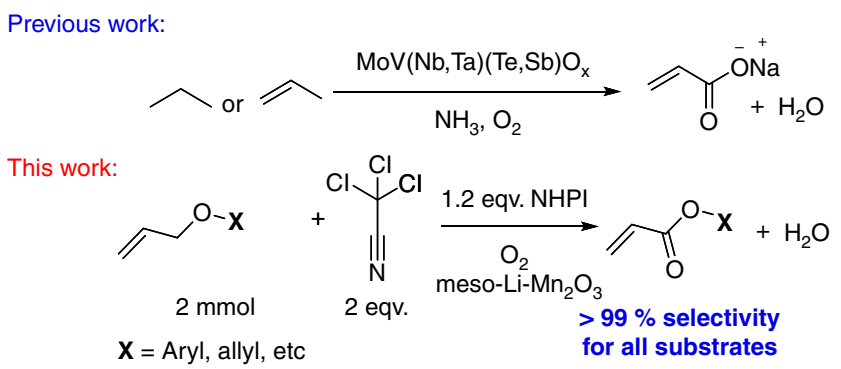

Fig. 1 Schematic representation of the plausible reaction mechanism in presence of PINO, MeCN, and $\mathrm{O}_{2}$. This mechanistic scheme identifies all of the reaction intermediates, shows the various surface manganese oxide species used in the catalytic reaction, and shows a detailed set of pathways that account for observed products
In summary, we have developed a low-temperature, heterogeneous catalytic aerobic oxidation procedure to form acrylates directly from allyl ethers using lithium ion impregnated mesoporous manganese oxide material. $\mathrm{Mn}$ being an earth-abundant element and $\mathrm{O}_{2}$ being the most abundant oxidant makes this catalytic reaction attractive. With diallyl ether we achieved a conversion of $95 \%$ to allyl acrylate with a selectivity of $>99 \%$ after extensive optimization of the reaction conditions. This revealed the crucial role of NHPI-air, hydrogen peroxides, and $\mathrm{CCl}_{3} \mathrm{CN}$ in promoting the activity of the catalyst. The interdependence of these promoting agents along with the catalyst in driving the catalytic process was interpreted by control experiments that led to a plausible mechanism. Mechanistic studies invoked the possibility of radical intermediate formation, followed by successive hydroxylation and oxidation. The presence of the $\mathrm{CCl}_{3} \mathrm{CN}$ promoted PINO radical and labile lattice oxygen of the meso- $\mathrm{Mn}_{2} \mathrm{O}_{3}$ material are the most important features of this catalytic process.

\section{Methods}

Catalysis. In this paper, we have developed a new catalytic approach to the mild aerobic partial oxidations of diallyl ether, see Fig. 2. Diallyl ether was chosen as a model substrate that could potentially suffer from (i) a double-bond shift and (ii) oxidation of the olefin to aldehyde or epoxide prior to the activation of allylic $\mathrm{C}-\mathrm{H}$ bond. We demonstrate the aerobic oxidation of allyl ethers to corresponding acrylate esters using various cation doped mesoporous manganese oxide materials The absence of any precious metal, easy isolation of the products, and the use of a reusable heterogeneous catalyst in the absence of acidic or alkaline media makes this process attractive for the oxidation of allyl ethers.

We initiated the oxidation of allyl ether in air as a model reaction to determine the optimal conditions. In our early screening attempts, we evaluated the impact of solvent on this oxidation. The results of our screening studies are presented in Supplementary Table 1 of the Supplementary information. Interestingly, no trace of the oxidized product was detected until tert-butylhydroperoxide (TBHP) was introduced (Supplementary Table 1, entry 1-4). Unsatisfactory conversion of allyl ether, even after using TBHP led us to employ a radical promoter. In 2010, Kamijo et al. ${ }^{31}$ successfully discovered the promotional activity of trichloroacetonitrile $\left(\mathrm{CCl}_{3} \mathrm{CN}\right)$ for m-CPBA (metachloroperbenzoic acid) in either oxidations. The high electrophilicity of the $\mathrm{CCl}_{3} \mathrm{CN}$ most likely promoted the homolytic cleavage of $\mathrm{O}-\mathrm{O}$ bonds of $m \mathrm{CPBA}$ by forming a highly unstable peroxyimidate adduct. The utilization of this hydroperoxide promoter $\left(\mathrm{CCl}_{3} \mathrm{CN}\right)$ as a solvent increased the

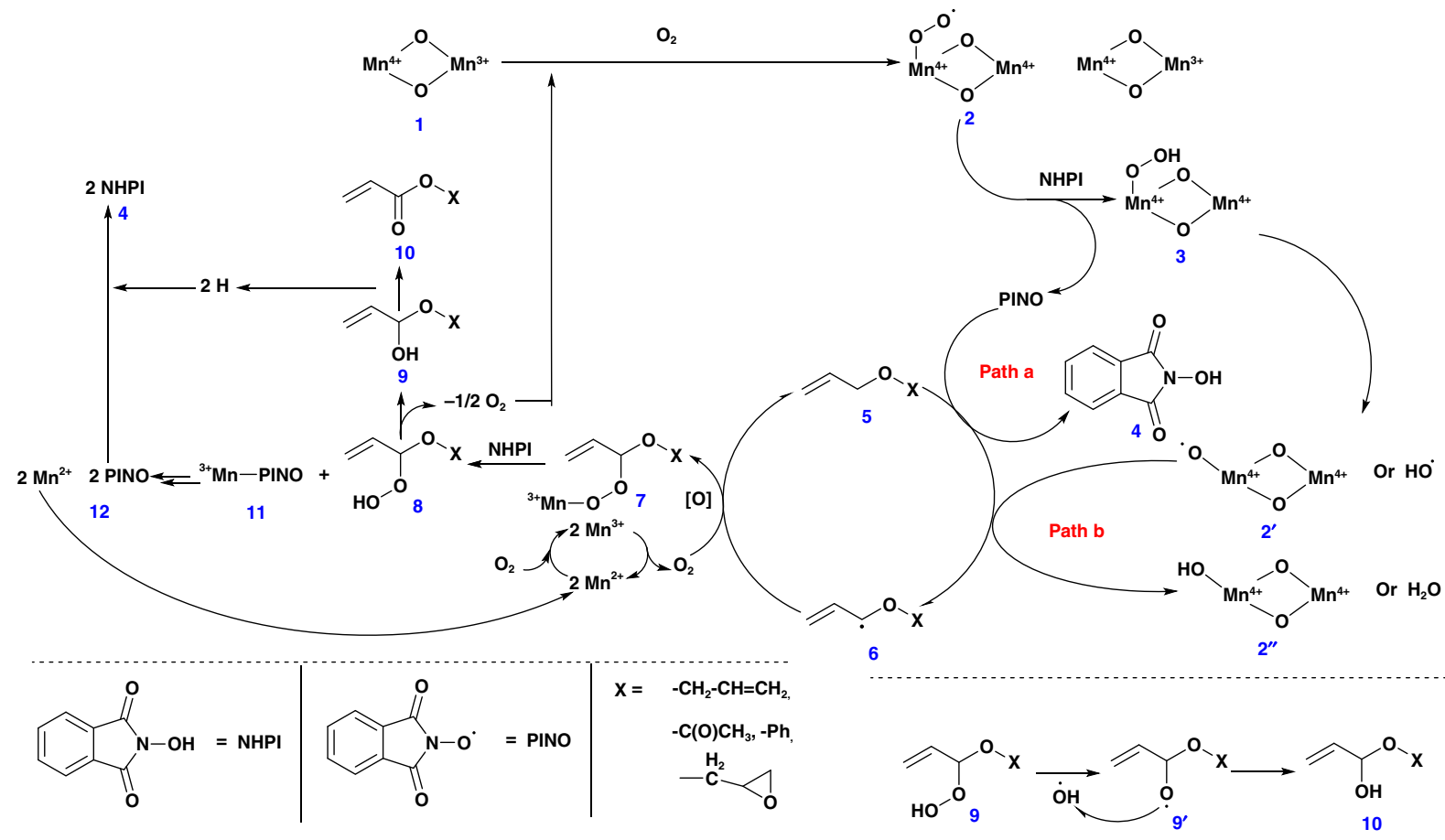

Fig. 2 This figure compares earlier mechanisms for acrylate formation using mixed metal oxides, oxygen, and ammonia versus this work using $N$ hydroxyphthalimide (NHPI), oxygen, and lithium manganese oxides which leads to enhanced (99\%) selectivity for all substrates $8-11$ 
product formation in our system to as high as $82 \%$ (Supplementary Table 1, entry 5). Further optimization of the amount of this promoter $\left(\mathrm{CCl}_{3} \mathrm{CN}\right)$ displayed similar results (81\% yield, Supplementary Table 1, entry 6$)$, indicating no dependence of reactivity on the amount of $\mathrm{CCl}_{3} \mathrm{CN}$ used. The role of $\mathrm{CCl}_{3} \mathrm{CN}$ was further validated by performing a solvent-free reaction with only $15 \%$ of the allyl ether converted (Supplementary Table 1, entry 7). The promising results of solvent optimization led to evaluation of other metal oxide supports. None were found to be as active as meso- $\mathrm{Mn}_{2} \mathrm{O}_{3}$ (81\% yield) (Supplementary Table 2, entry 1-4) with at most $20 \%$ yield observed for the other supports. Better accessibility of the labile lattice oxygens and comparatively lower binding energy of metal-oxygen bonds resulted in higher yields ${ }^{20}$. Reactions using $\mathrm{Mn}^{3+}$-enriched species (such as c$\mathrm{Mn}_{2} \mathrm{O}_{3}$ and $\left.\mathrm{Mn}(\mathrm{OAc})_{3}\right)$ showed better conversions than both the $\mathrm{Mn}^{2+}$-rich and catalyst-free systems (Supplementary Table 2, entry 6-9). The homogeneous reaction performed in the presence of a $\mathrm{Mn}^{3+}$-enriched $\left(\mathrm{Mn}(\mathrm{OAc})_{3}\right)$ species demonstrated lower yields (only $13 \%$ ) than its heterogeneous counterpart (c$\mathrm{Mn}_{2} \mathrm{O}_{3}$ ), which was probably due to the lack of lattice oxygens in the homogeneous systems. Moreover, a heterogeneous system can adsorb the substrate (allyl ether) prior to oxidation with lattice oxygens, which is not possible in a homogeneous system. The presence of $1 \mathrm{~mol} \%$ of electropositive $\mathrm{Cs}^{+}$ions in mesoporous manganese oxide increased the oxidative property of the material by 100 times for alcohol to aldehyde and amine to imine formation ${ }^{20,26}$. This spurred us to investigate the effect of alkali and alkaline earth metal ions on the heterogeneous meso- $\mathrm{Mn}_{2} \mathrm{O}_{3}$ system. Nearly all showed an enhancement in activity

(Supplementary Table 3). Enhancement of the surface basicity of the material due to the incorporation of alkali and alkaline earth metal ions is a likely reason for this excellent activity. Introduction of these electropositive alkali and alkaline earth metal ions on the surface are potentially known to cause both surface defects and accumulation of negative charges, which enhance the surface basicity ${ }^{32}$. This inspired us to evaluate the effect of different alkali and alkali metal ions. $\mathrm{Li}$ impregnated meso- $\mathrm{Mn}_{2} \mathrm{O}_{3}$ (meso- $\mathrm{Li}-\mathrm{Mn}_{2} \mathrm{O}_{3}$ ) emerged as the best catalyst with a yield of $92 \%$ (Supplementary Table 3, entry 1) and a selectivity of $>99 \%$. Perhaps, due to the higher charge density of $\mathrm{Li}^{+}$ions, their bonding on the manganese oxide surface was enhanced. $\mathrm{Li}^{+}$, the smallest ion, could also favor the introduction of more ions onto the surface of manganese oxide nanoparticles and lead to the best activity. The effect of other peroxides was explored in the presence of a catalyst. Benzoyl peroxide appears to be a suitable alternative to TBHP, converting $90 \%$ of the allyl ether (Supplementary Table 4, entry 1-6). Despite these high yields, multiple side products from the peroxides were observed. To minimize these side products, $N$-hydroxyphthalimide (NHPI) was used as it is known for its powerful oxidizing ability in combination with transition metals ${ }^{13-15,33}$. This species converted $95 \%$ of the allyl ether to the expected monoester with $>99 \%$ selectivity, and fewer side products than before (Supplementary Table 4, entry 7).

Consequently, NHPI in air was considered to be the most promising oxidant for this system. Furthermore, adjusting the NHPI amount beyond $25 \mathrm{~mol} \%$

(Supplementary Table 5) did not show a detectable difference in the performance of the system. After extensive screening (see the supporting information), the best catalytic system was achieved with $1 \mathrm{~mol} \% \mathrm{Li}$ ion on meso- $\mathrm{Mn}_{2} \mathrm{O}_{3}$ catalyst, in the presence of $25 \mathrm{~mol} \%$ of NHPI, in air with a minimum of two equivalents of $\mathrm{CCl}_{3} \mathrm{CN}$ in acetonitrile at $80{ }^{\circ} \mathrm{C}(95 \%$ conversion and $>99 \%$ selectivity).

Mechanistic studies. Once the catalytic system was optimized, additional experiments were performed to further investigate the mechanistic details of the catalytic process. The experiment in the presence of NHPI and metal oxide catalyst was initially performed in the presence of a radical promoter $\mathrm{CCl}_{3} \mathrm{CN}$. $\mathrm{CCl}_{3} \mathrm{CN}$ is expected to promote the activity of hydroperoxide radicals. A detectable drop in conversion from 95 to $80 \%$ was noticed when $\mathrm{CCl}_{3} \mathrm{CN}$ was excluded (Supplementary Table 4 , entry 9). This suggests that $\mathrm{CCl}_{3} \mathrm{CN}$ promotes the generation of $\mathrm{N}$-hydroxides to form $\mathrm{N}$-oxide radicals. Interestingly, only $6 \%$ of the product formation was detected when air or oxygen was replaced by nitrogen in the presence of NHPI (Supplementary Table 4, entry 10). This confirmed the role of air in promoting formation of the PINO radical from NHPI. In addition, this small but significant activity under a nitrogen atmosphere ( $18 \%$ conversion) implied that the aerobic oxygens were not the terminal oxidants. An oxidant which causes the termination of a catalytic process is called the terminal oxidant. The nitrogen atmosphere affected the reaction by slowing down the kinetics of PINO formation. Evaluating the terminal oxidant for an oxidation reaction is essential in controlling kinetics. To further probe the mechanism, the $\mathrm{CCl}_{3} \mathrm{CN}$ promoter was excluded from a reaction conducted in a nitrogen atmosphere and the conversion of allyl ether almost fully diminished (as low as $3 \%$, Supplementary Table 4, entry 11). These latter experiments suggest the combined effect of oxygen and $\mathrm{CCl}_{3} \mathrm{CN}$ in promoting the PINO radical from NHPI. Despite the synergistic effect between those reaction parameters in oxidizing the $\alpha-\mathrm{C}-\mathrm{H}$ bond of allyl ether, a search for terminal oxidant of the process was continued.

Therefore, further investigations were continued with specific oxidants to identify the terminal oxidant. Some reactions were also performed under catalystfree conditions. The reactivity of oxidant NHPI-air under catalyst-free conditions was found to convert only $12 \%$ and converted only $3 \%$ when $\mathrm{CCl}_{3} \mathrm{CN}$ and $\mathrm{CH}_{3} \mathrm{CN}$, the solvent, were excluded (Supplementary Table 4, compare entry 7-12, and 12-14). This further proved the importance of $\mathrm{CCl}_{3} \mathrm{CN}$ as the promoter besides demonstrating that NHPI-air is the nonterminal oxidant. Reactions using air as the sole oxidant were also evaluated. The reaction with air and catalyst converted around $4 \%$ of the allyl ether to the monoester and not observed under corresponding catalyst-free conditions (Supplementary Table 4, compare entry 15-16). This confirmed that lattice oxygens of the catalyst were the terminal oxidants.

\section{Data availability}

The data that support the findings of this study are available from the corresponding author upon reasonable request.

Received: 10 March 2018 Accepted: 18 January 2019

Published online: 08 February 2019

\section{References}

1. Zhang, Z., Qu, Y., Wang, S. \& Wang, J. Catalytic performance and characterization of silica supported sodium phosphates for the dehydration of methyl lactate to methyl acrylate andacrylic acid. Ind. Eng. Chem. Res. 48, 9083-9089 (2009).

2. Lee, J. M. et al. Efficient dehydration of methyl lactate to acrylic acid using $\mathrm{Ca}$ 3(PO4)2-SiO2 catalyst. Catal. Commun. 11, 1176-1180 (2010).

3. Zhang, J. et al. Efficient acrylic acid production through bio lactic acid dehydration over $\mathrm{NaY}$ Zeolite modified by alkali phosphates. ACS Catal. 1, 32-41 (2011).

4. Jamróz, M. H., Jamróz, M. E., Rode, J. E., Bednarek, E. \& Dobrowolski, J. C. Interpretation of vibrational and NMR spectra of allyl acrylate: An evidence for several conformers. Vib. Spectrosc. 50, 231-244 (2009).

5. Agarwal, Y. K., Kaushik, S. D. \& Kumar, P. C. Synthesis and rheological studies of methacrylic acid-ethyl acrylate-allyl methacrylate terpolymers. J. Macromol. Sci. Part A 44, 877-880 (2007).

6. Collins, J. P. et al. Catalytic dehydrogenation of propane in hydrogen permselective membrane reactors. Ind. Eng. Chem. Res. 35, 4398-4405 (1996).

7. Clarke, A.F. Process of making alkyl acrylates. U. S. Patent 2,464,364A. 1-3 (1943).

8. Korovchenko, P. et al. M1 to M2 phase transformation and phase cooperation in bulk mixed metal Mo-V-M-O $(\mathrm{M}=\mathrm{Te}, \mathrm{Nb})$ catalysts for selective ammoxidation of propane. Top. Catal. 50, 43-51 (2008).

9. Guliants, V. V. et al. Roles of surface $\mathrm{Te}, \mathrm{Nb}$, and $\mathrm{Sb}$ oxides in propane oxidation to acrylic acid over bulk orthorhombic Mo-V-O phase. J. Phys. Chem. B 109, 24046-24055 (2005).

10. Guerrero-Pérez, M. O., Peña, M. A., Fierro, J. L. G. \& Bañares, M. A. A study about the propane ammoxidation to acrylonitrile with an alumina-supported Sb-V-O catalyst. Ind. Eng. Chem. Res. 45, 4537-4543 (2006).

11. Amakawa, K. et al. Multifunctionality of crystalline $\mathrm{MoV}(\mathrm{TeNb}) \mathrm{M} 1$ oxide catalysts in selective oxidation of propane and benzyl alcohol. ACS Catal. 3, 1103-1113 (2013).

12. Brazdil, J. F. in Ullmann's Encyclopedia of Industrial Chemistry (Wiley-VCH Verlag GmbH \& Co. KGaA, Weinheim, 2000)

13. Ishii, Y., Sakaguchi, S. \& Iwahama, T. Innovation of hydrocarbon oxidation with molecular oxygen and related reactions. Adv. Synth. Catal. 343, 393-427 (2001).

14. Horn, E. J. et al. Scalable and sustainable electrochemical allylic C-H oxidation. Nature 533, 77-81 (2016).

15. Hruszkewycz, D. P., Miles, K. C., Thiel, O. R. \& Stahl, S. S. Co/NHPI-mediated aerobic oxygenation of benzylic $\mathrm{C}-\mathrm{H}$ bonds in pharmaceutically relevant molecules. Chem. Sci. 8, 1282-1287 (2017).

16. Son, Y., Makwana, V. D., Howell, A. R. \& Suib, S. L. Efficient, catalytic, aerobic oxidation of alcohols with octahedral molecular sieves. Angew. Chem. 113, 4410-4413 (2001)

17. Opembe, N. N., Son, Y.-C., Sriskandakumar, T. \& Suib, S. L. Kinetics and mechanism of $9 \mathrm{H}$-fluorene oxidation catalyzed by manganese oxide octahedral molecular sieves. ChemSusChem 1, 182-185 (2008).

18. Ghosh, R. et al. Role of manganese oxide octahedral molecular sieves in styrene epoxidation. J. Phys. Chem. B 110, 7592-7599 (2006).

19. Yamaguchi, K., Kobayashi, H., Oishi, T. \& Mizuno, N. Catalytic amide synthesis heterogeneously catalyzed synthesis of primary amides directly from primary alcohols and aqueous ammonia. Angew. Chem. 124, 559-562 (2012).

20. Biswas, S. et al. Aerobic oxidation of amines to imines by cesium-promoted mesoporous manganese oxide. ACS Catal. 5, 4394-4403 (2015).

21. Biswas, S. et al. Mesoporous copper / manganese oxide-catalyzed coupling of alkynes: evidence for synergistic cooperative catalysis. ACS Catal. 6 , 5069-5080 (2016).

22. Yamaguchi, K., Wang, Y., Oishi, T., Kuroda, Y. \& Mizuno, N. Heterogeneously catalyzed aerobic cross-dehydrogenative coupling of 
terminal alkynes and monohydrosilanes by gold supported on oms-2. Angew. Chem. Ed. 52, 5627-5630 (2013).

23. Dutta, B. et al. Mesoporous manganese oxide catalyzed aerobic oxidative coupling of anilines to aromatic azo compounds. Angew. Chem. 55, 2171-2175 (2016).

24. Jin, L. et al. Studies on dehydrogenation of ethane in the presence of $\mathrm{co} 2$ over octahedral molecular sieve (OMS-2) catalysts. Chem. Cat. Chem. 1, 441-444 (2009).

25. Suib, S. L. Porous manganese oxide octahedral molecular sieves and octahedral layered materials. Acc. Chem. Res. 41, 479-487 (2008).

26. Biswas, S. et al. Ion induced promotion of activity enhancement of mesoporous manganese oxides for aerobic oxidation reactions. Appl. Catal. B Environ. 165, 731-741 (2015).

27. Poyraz, A. S., Kuo, C.-H., Biswas, S., King'ondu, C. K. \& Suib, S. L. A general approach to crystalline and monomodal pore size mesoporous materials. Nat. Commun. 4, 1-10 (2013).

28. Ishii, Y. \& Sakaguchi, S. A new strategy for alkane oxidation with $\mathrm{O}_{2}$ using Nhydroxyphthalimide (NHPI) as a radical catalyst. Catal. Surv. Jpn. 3, 27-35 (1999).

29. Biswas, $S$. et al. Heterogeneous catalytic oxidation of amides to imides by manganese oxides. Sci. Rep. 8, 13649 (2018).

30. Lin, S.-S. \& Gurol, M. D. Catalytic decomposition of hydrogen peroxide on iron oxide: kinetics, mechanism, and implications. Environ. Sci. Technol. 32, 1417-1423 (1998).

31. Kamijo, S., Matsumura, S. \& Inoue, M. $\mathrm{CCl} 3 \mathrm{CN}$ : a crucial promoter of $\mathrm{M}$ CPBA-mediated direct ether oxidation. Org. Lett. 12, 4195-4197 (2010).

32. Helwani, Z., Othman, M. R., Aziz, N., Kim, J. \& Fernando, W. J. N. Solid heterogeneous catalysts for transesterification of triglycerides with methanol: A review. Appl. Catal. A: Gen. 363, 1-10 (2009).

33. Sheldon, R. A. \& Arends, I. W. C. E. Organocatalytic oxidations mediated by nitroxyl radicals. Adv. Synth. Catal. 346, 1051-1071 (2004).

\section{Acknowledgements}

We thank ExxonMobil Research and Engineering Company for support of this research. Partial support of this research was provided by the US Department of Energy, Office of Basic Energy Sciences, Division of Chemical, Biological and Geological Sciences under grant DE-FG02-86ER13622.A000.

\section{Author contributions}

B.D., P.N., and S.L.S. designed the experiments. B.D. synthesized the materials and conducted the catalytic reactions. R.C. performed some initial experiments and isolated the products. S.R. and T.D.S. performed computational studies and provided valuable insights. L.A. performed the electron paramagnetic resonance (EPR) experiments. S.L.S and P.N. were the project coordinators. B.D., P.N., and S.L.S. prepared the paper. All authors have read and approved the final paper.

\section{Additional information}

Supplementary Information accompanies this paper at https://doi.org/10.1038/s41467019-08619-x.

Competing interests: The authors declare no competing interests.

Reprints and permission information is available online at http://npg.nature.com/ reprintsandpermissions/

Journal peer review information: Nature Communications thanks Weijie Ji and the other anonymous reviewers for their contribution to the peer review of this work.

Publisher's note: Springer Nature remains neutral with regard to jurisdictional claims in published maps and institutional affiliations.

cc (i) Open Access This article is licensed under a Creative Commons Attribution 4.0 International License, which permits use, sharing, adaptation, distribution and reproduction in any medium or format, as long as you give appropriate credit to the original author(s) and the source, provide a link to the Creative Commons license, and indicate if changes were made. The images or other third party material in this article are included in the article's Creative Commons license, unless indicated otherwise in a credit line to the material. If material is not included in the article's Creative Commons license and your intended use is not permitted by statutory regulation or exceeds the permitted use, you will need to obtain permission directly from the copyright holder. To view a copy of this license, visit http://creativecommons.org/ licenses/by/4.0/.

(c) The Author(s) 2019 